\title{
Clinical Features, Bacteriology, and Antibiotic Treatment Among Patients with Presumed Naja Bites in Vietnam
}

\author{
Ngoc Duc Ngo, $\mathrm{PhD}^{1,2}$; Quy Xuan Le, $\mathrm{MD}^{1}$; Anh Quang Pham, MD ${ }^{1}$; Nguyen Trung Nguyen, $\mathrm{PhD}^{3}$; \\ Hung Tran $\mathrm{Ha}, \mathrm{PhD}^{1,3}$; Michael Minh Quoc Dinh, $\mathrm{PhD}^{4}$; Thuan Quang Le, $\mathrm{PhD}^{3}$ \\ ${ }^{1}$ Department of Emergency and Poison Control, Hanoi Medical University, Hanoi, Vietnam; ${ }^{2}$ Emergency Department, Bach Mai Hospital, Hanoi, Viet- \\ nam; ${ }^{3}$ Poison Control Center, Bach Mai Hospital, Hanoi, Vietnam; ${ }^{4}$ Sydney Medical School, University of Sydney, Hoc Mai Foundation, Sydney, \\ Australia
}

\begin{abstract}
Introduction-Clinical and bacteriological features of cobra (Naja) bites are still relatively unknown in Vietnam. This study aimed to characterize the clinical and bacteriological characteristics of local wounds in patients with presumed Naja spp bite, as well as their antibiotic treatment.

Methods-A cross-sectional study was performed on presumed Naja bite patients who were admitted to Bach Mai Hospital in Hanoi, Vietnam. In vitro bacterial isolation, blood tests, and lesion measure were conducted, and antibiotic susceptibilities of localized bite wounds were assessed. The Mann-Whitney test was used to examine the difference in clinical characteristics between patients experiencing presumed Naja atra bites and Naja kaouthia bites. Data are presented as percentages or median with interquartile range, as appropriate. Statistical significance was accepted at $P<0.05$.

Results-Among 46 patients, all had typical clinical features of Naja bite. The median bite-to-hospital time was $6 \mathrm{~h}$ (interquartile range 4.0-11.3). The dominant organisms isolated from local wounds were Morganella morganii (11/36) and Enterococcus faecalis (25/36). All cultures were susceptible to ciprofloxacin. No difference was found with regard to pain, swelling circumference, swelling spread, or necrotic area between patients bitten by presumed Naja atra and Naja kaouthia $(P>0.05)$.

Conclusions-Wound necrosis and infection were important clinical issues in presumed Naja spp snake bites. Morganella morganii and Enterococcus faecalis were dominant in local wound swabs of such cases. Ciprofloxacin should be an effective first-line antibiotic for patients with presumed Naja bite.

Keywords: snakebite, antibiotic susceptibility, Morganella morganii, Enterococcus faecalis, ciprofloxacin
\end{abstract}

\section{Introduction}

Snakebites are an important health issue in many countries with warm and humid climates. According to the World Health Organization, it is estimated that there are 5.4 million victims of snakebite each year, with half of them being associated with venomous snakes; approximately 81,000 to 138,000 deaths; and more than 100,000 people experience severe sequelae. ${ }^{1}$ The number of people

Corresponding author: Ngoc Ngo Duc, PhD, Department of Emergency and Poison Control, Hanoi Medical University, Hanoi, Vietnam; Emergency Department, Bach Mai Hospital, Hanoi, Vietnam; e-mail: ngoducngoc.bm@gmail.com.

Submitted for publication May 2019.

Accepted for publication January 2020. affected by venomous snakebites in Asian countries is higher than on other continents, with around 2 million cases reported each year. ${ }^{1}$ Venomous snakebites often lead to local wound necrosis and secondary wound infection. ${ }^{2}$ Severity of venomous snakebite varies from very mild bites to severe, life-threatening envenomation, requiring initial management and emergency recovery. Treatment of venomous snakebites depends on the morphological, biological, toxicological, and clinical characteristics of each venomous snake.

In Vietnam, the 3 major Naja spp are Naja atra, Naja kaouthia, and Naja siemensis. Among these, Naja atra is the dominant species of cobra in Northern Vietnam. ${ }^{3}$ Annually, approximately 30,000 cases of venomous snakebite are reported, and the incidence 
of Naja bites is 5 per 100,000 person-years. ${ }^{4}$ However, these figures are likely underestimated because many cases that occur in rural areas are not reported or are treated by traditional methods. Although Naja bites remain common in Vietnam, wound bacteriology and antibiotic indication have not been studied. In this study, we aimed to describe the clinical and bacteriological characteristics of local wounds in patients with presumed Naja bite, as well as their antibiotic treatment, which may influence local clinical guidelines for snake wound infection management.

\section{Methods}

\section{STUDY DESIGN AND SAMPLING METHOD}

A cross-sectional study was conducted of patients with presumed Naja bites at the Bach Mai Hospital, the largest tertiary referral hospital in Hanoi, Vietnam, from September 2017 to September 2018. Patients were recruited if 1) they reported that they were bitten by a snake; 2) the snake was brought to and identified by the physicians at the poison control center of Bach Mai Hospital or patients had clinical evidence of wound infection after Naja spp bite occurrence; 3 ) specialist toxicology physicians identified patients' wounds as due to Naja spp bite via fang mark, swelling, and necrosis; and 4) patients agreed to participate in the study.

We applied the characteristics of snakes and wounds that were consistent with wounds observed in previous patients envenomed by Naja spp to identify patients with Naja bites. For Naja atra, the color of snake varies and includes brown, gray, and black. The back of the hood features 1 or 2 white marks with black dots in the middle resembling 1 or a pair of eyes, with a blackish green border. Snake venom causes soreness, local swelling, diffuse edema, and gangrene. In the first $24 \mathrm{~h}$ there may be blisters and watery and dark spots. For Naja kaouthia, the color varies from olive green to black. The back of the hood has a monocellate pattern, and the belly is usually pale yellow or green with black rings. The venom causes edema, necrosis, or other symptoms such as headache, nausea, and abdominal pain.

Patients were excluded if they 1) used prophylactic antibiotics before hospital admission or 2) refused to participate in the study. All participants brought snakes for identification (ID) verification. A toxicologist (NDN) who was familiar with Naja and had experience with ID of field specimens was consulted to identify the snakes. Patients provided written informed consent before enrollment. The study was approved by the institutional review board of Bach Mai hospital.

\section{DATA MEASUREMENT}

\section{Microbiology isolation}

After patients were admitted to the hospital with purulence and abscess, a sample of wound purulence was extracted by using sterile swab sticks (Huang Yu Company) and was sent to the microbiology department of Bach Mai Hospital within $1 \mathrm{~h}$. The sample was isolated using the VITEK 2 system (BioMérieux, Inc., Durham, NC). Antibiogram was conducted by the Kirby-Bauer method. Antibiotic susceptibility test was assessed according to the Clinical \& Laboratory Standards Institute criteria.

Blood tests were conducted only when patients were admitted to the hospital. The tests included total blood count (white blood cell count $\left[\mathrm{g} \cdot \mathrm{L}^{-1}\right]$, neutrophils [\%], red blood cell count $\left[\mathrm{T} \cdot \mathrm{L}^{-1}\right]$, hemoglobin $\left[\mathrm{g} \cdot \mathrm{L}^{-1}\right]$, platelet $\left[\mathrm{G} \cdot \mathrm{L}^{-1}\right]$, coagulation profile [prothrombin time $\left.(\%)\right]$, activated partial thromboplastin time [s], fibrinogen, procalcitonin $\left.\left[\mathrm{ng} \cdot \mathrm{mL}^{-1}\right]\right)$ and C-reactive protein $\left.\left(\mathrm{mg} \cdot \mathrm{L}^{-1}\right]\right)$.

\section{Lesion measurement}

In this study, indicators including swelling circumference $(\mathrm{cm})$, swelling spread $(\mathrm{cm})$, necrotic area $\left(\mathrm{cm}^{2}\right)$, and pain severity were measured. The swelling circumference was calculated as the difference between the circumference of the limb through the bite and the circumference of the healthy parallel limb. The swelling spread was defined as the distance from center of the bite to the swelling margin. Necrotic area was estimated using a grid board. Pain severity was assessed by the numeric pain rating scale. The typical symptoms of wound infection included increasing pain in the lesion area, edema, erythema, heat, purulence/ abscess, purulent exudate, and delayed healing. ${ }^{5,6}$ The clinical severity of envenomation was assessed using the European Association of Poisons Centres and Clinical Toxicologists Poisoning Severity Score (Table 1). ${ }^{7}$

All patients received initial antibiotics by the on-call chief physician for prophylaxis when they were admitted to the hospital before antibiotic sensitivities were established. Appropriate initial antibiotics were defined as antibiotics used within $24 \mathrm{~h}$ of the first encounter when in vitro tests confirmed an existence of infection.

\section{STATISTICAL ANALYSIS}

$\mathrm{R}$ version 3.5.1 programming language (The $\mathrm{R}$ Foundation) was used to analyze the data. Median and interquartile range were used because data had nonnormal distribution. The Mann-Whitney test was used to examine the difference in clinical characteristics between patients with presumed Naja atra bites and Naja kaouthia bites. $P$ values $<0.05$ were considered statistically significant. 
Table 1. Grades of envenomation according to the European Association of Poisons Centres and Clinical Toxicologists Poisoning Severity Score

\begin{tabular}{ll}
\hline Grade & Signs and symptoms \\
\hline 0 & Fang marks, swelling, and erythema around the fang mark $<2.5 \mathrm{~cm}$; minimal pain and tenderness; no systemic symptoms \\
1 & Fang marks; history of immediate pain with the bite; swelling and erythema $5-15 \mathrm{~cm}$; no systemic signs or symptoms \\
2 & $\begin{array}{l}\text { Fang marks; history of immediate severe pain; swelling and erythema } 15-40 \mathrm{~cm} \text {; mild systemic symptoms and/or } \\
\text { abnormal laboratory findings }\end{array}$ \\
& $\begin{array}{l}\text { Fang marks; history of immediate severe pain; swelling and erythema }>40 \mathrm{~cm} \text {; petechiae and bullae; moderate systemic } \\
\text { symptoms; bleeding and/or disseminated intravascular coagulopathy; abnormal laboratory values }\end{array}$ \\
& $\begin{array}{l}\text { Fang marks; signs of multiple envenomation sites; history of immediate severe pain; severe systemic signs, possibly } \\
\text { including coma, shock, bleeding, disseminated intravascular coagulation, and paralysis }\end{array}$ \\
\hline
\end{tabular}

\section{Results}

All 46 cases had toxicity symptoms, and patients with level 2 severity were dominant (Table 2). No patient was found to be anemic, thrombocytopenic, coagulopathic, or in acute renal failure. Patients had elevated neutrophil counts, but procalcitonin and C-reactive protein levels were not increased.

Table 3 shows that no difference was found in pain $(P=0.23)$, swelling circumference $(P=0.73)$, swelling spread $(P=0.35)$, or necrotic area $(P=0.48)$ between patients bitten by presumed Naja atra and Naja kaouthia.

Positive bacterial wound cultures were found in $80 \%$ of cases. There were 48 strains of bacteria isolated from bite wound specimens taken. Enterococcus faecalis and Morganella morganii were the most common strains isolated. Cultivation results suggested that gram-positive aerobic bacterial growth was more frequent than gram-negative aerobic bacterial growth (Table 4).

Isolated Enterococcus faecalis was susceptible to all antibiotics. Staphylococcus aureus bacteria were resistant to penicillin but sensitive to methicillin. Morganella morganii isolates were sensitive to third- and fourth-generation cephalosporins, carbapenem, piperacillin/tazobactam, fluoroquinolones, gentamicin, and amikacin. The strains of Enterobacter spp, Proteus, Klebsiella pneumoniae, and Raoultella planticola were sensitive to third- and fourth-generation cephalosporins, carbapenem groups, piperacillin/tazobactam, fluoroquinolone, gentamicin, and amikacin. Pseudomonas putida was sensitive to ceftazidime, amikacin, levofloxacin, and doxycycline but resistant to meropenem (Table 5).

Most patients received initial antibiotics in accordance with antimicrobial guidelines. Two patients were recorded as having inappropriate initial antibiotic use; cultures from infected wounds were positive for S aureus and Pseudomonas putida.
Table 2. Clinical and paraclinical characteristics

\begin{tabular}{ll}
\hline Clinical variables & Median $($ IQR $)$ \\
\hline NRS & $6(5-7)$ \\
Swelling circumference $(\mathrm{cm})$ & $2(1.0-2.3)$ \\
Necrotic area $\left(\mathrm{cm}^{2}\right)$ & $10.5(4.0-22.5)$ \\
Swelling spread $(\mathrm{cm})$ & $21.5(15.0-38.8)$ \\
Envenomation grade & \\
$\quad 1$ & $6(13 \%)$ \\
2 & $29(63 \%)$ \\
3 & $10(22 \%)$ \\
$\quad 4$ & $2(2 \%)$ \\
Bite-to-hospital time $(\mathrm{h})$ & $6(4-11)$ \\
Paraclinical variables & \\
RBC $\left(\mathrm{T} \cdot \mathrm{L}^{-1}\right)$ & $4.9(4.7-5.4)$ \\
Hemoglobin $\left(\mathrm{g} \cdot \mathrm{L}^{-1}\right)$ & $150(138-159)$ \\
Platelet $\left(\mathrm{G} \cdot \mathrm{L}^{-1}\right)$ & $239(200-355)$ \\
PT $(\%)$ & $89(74-96)$ \\
aPTT $(\mathrm{s})$ & $25(23-27)$ \\
Fibrinogen & $3.6(2.8-4.3)$ \\
WBC $\left(\mathrm{G} \cdot \mathrm{L}^{-1}\right)$ & $14.7(8.9-17.9)$ \\
Neutrophils $(\%)$ & $86(79-90)$ \\
Procalcitonin $\left(\mathrm{ng} \cdot \mathrm{mL}^{-1}\right)$ & $0.3(0.1-0.6)$ \\
CRP $\left(\mathrm{mg} \cdot \mathrm{L}^{-1}\right)$ & $0.5(0.1-4.1)$ \\
\hline
\end{tabular}

aPTT, activated partial thromboplastin time; CRP, C-reactive protein; IQR, interquartile range; NRS, numeric rating scale for pain; $\mathrm{PT}$, prothrombin time; RBC, red blood cell count; WBC, white blood cell count.

\section{Discussion}

In this study, we observed that most of our patients were bitten on the foot after accidentally treading on a snake or walking near a snake lair while working in the field or jungle. This result was similar to a Hong Kong study in which the authors indicated that lower limb was the most common site of bite. ${ }^{8}$

All patients in the present study had swelling, necrosis, and local pain typical of Naja spp bites. Local wound necrosis and intense pain associated with Naja envenomation were thought to be mediated by cytotoxins and 
Table 3. Clinical characteristics between 2 types of snake

\begin{tabular}{|c|c|c|c|c|}
\hline \multirow[t]{2}{*}{ Variable } & \multirow{2}{*}{$\frac{\text { Total }}{46}$} & \multirow{2}{*}{$\frac{\text { Natra atra }}{33}$} & \multirow{2}{*}{$\frac{\text { Natra kaouthia }}{13}$} & \multirow[t]{2}{*}{$\mathrm{P}$ value } \\
\hline & & & & \\
\hline \multicolumn{5}{|l|}{ NRS } \\
\hline Median (IQR) & $6(5-7)$ & $6(5-7)$ & $6(6-8)$ & 0.23 \\
\hline Range & $4-9$ & $4-9$ & $4-9$ & \\
\hline \multicolumn{5}{|l|}{ Swelling (cm) } \\
\hline Median (IQR) & $2.0(1.0-2.3)$ & $2.0(1.0-2.5)$ & $2.0(1.0-2.5)$ & 0.73 \\
\hline Range & $1-4$ & $1-4$ & $1-3$ & \\
\hline \multicolumn{5}{|c|}{ Necrotic area $\left(\mathrm{cm}^{2}\right)$} \\
\hline Median (IQR) & $11(4-23)$ & $11(4-17)$ & $10(6-45)$ & 0.48 \\
\hline Range & $1-300$ & $1-200$ & $1-300$ & \\
\hline \multicolumn{5}{|c|}{ Swelling spread (cm) } \\
\hline Median (IQR) & $22(15-39)$ & $20(15-31)$ & $27(15-52)$ & 0.35 \\
\hline Range & $10-78$ & $10-78$ & $10-65$ & \\
\hline
\end{tabular}

IQR, interquartile range; NRS, numeric rating scale for pain.

Table 4. Isolated bacteria of local wound

\begin{tabular}{ll}
\hline Cultures & $n(\%)$ \\
\hline Positive cultures & $\mathbf{3 6}(\mathbf{7 8 )}$ \\
Gram-negative & $11(31)$ \\
$\quad$ Morganella morganii & $4(11)$ \\
$\quad$ Enterobacter spp & $2(6)$ \\
Proteus spp & $1(3)$ \\
Raoultella planticola & $1(3)$ \\
Klebsiella pneumoniae & $1(3)$ \\
Pseudomonas putida & \\
Gram-positive & $25(69)$ \\
$\quad$ Enterococcus faecalis & $1(3)$ \\
$\quad$ Staphylococcus aureus &
\end{tabular}

proteolysis through so-called "three finger" toxins and phospholipase A2. ${ }^{9,10}$ In addition to pain and necrosis, swelling was very common in our study and occurred in all cases, consistent with previous studies. ${ }^{8,11,12}$ The median swelling circumference was approximately $2 \mathrm{~cm}$ greater than the corresponding site on the normal limb, and the median necrotic area and swelling spread were $11 \mathrm{~cm}$ and $22 \mathrm{~cm}$, respectively. These features would be potentially useful to measure treatment progress. In this study, 10 of 46 patients $(22 \%)$ had infection without developing an abscess. Some factors could contribute to these features, including time from the bite to hospital admission, local wound severity, and necrotic area. For the patients with severe local wound, infection, and necrosis and delayed hospital admission, we did not use antivenom serum but instead transferred them to the operating room to clean and remove necrotic tissues.

In our study, 39 of 46 patients $(85 \%)$ were transferred to the hospital within $24 \mathrm{~h}$ after being bitten. Bite-to-hospital time is a factor in assessing severity because toxins can enter systemic circulation within an hour. ${ }^{9-11,13}$ One of our patients was a 25-y-old woman who was bitten on the foot and treated with traditional medicines at home. After $72 \mathrm{~h}$, she was admitted to the nearest local health facility. She was subsequently intubated and transferred to the Poison Control Center of Bach Mai Hospital and required mechanical ventilation for $2 \mathrm{~d}$. The necrotic area was approximately $15 \times 20 \mathrm{~cm}$ at the time of admission. Results of localized wound isolates grew $P$ putida. Excision of necrotic tissues was performed 2 days after admission. She recovered well but was left with a limping gait due to lower limb local damage.

Leucocytosis and neutrophilia occurred in 32 patients at the time of admission, resulting from the initial immune response to the toxins and wound infection. Naja oral bacterial flora contain various aerobic and anaerobic bacteria. ${ }^{2,14}$ In Thailand, Enterobacter, Pseudomonas, and Staphylococcus spp were the most common aerobic bacteria, and Clostridium was the most common anaerobic bacteria in the Malayan viper (Calloselasma rhodostoma) oral cavity. ${ }^{15}$ In the Naja oral cavity, M morganii and Enterococcus are the most common bacteria. ${ }^{2}$ The positive culture isolation rate was $78 \%$ (36 of 46), of which 28 of $36(58 \%)$ were gram positive and $20(42 \%)$ were gram negative. Eleven isolated cultures were positive for more than 1 bacterium. The dominant bacteria isolated were $E$ faecalis (25 of 36) and $M$ morganii (11 of 36), consistent with a study in Taiwan, ${ }^{15}$ whereas $S$ aureus and Escherichia coli were the most common isolated bacteria in a study from India. ${ }^{16}$ This difference might be explained by differences in geography, environment, and prey. Notably, 22\% had negative results, 
Table 5. Antibiogram with antibiotic susceptibility

\begin{tabular}{|c|c|c|c|c|c|c|c|c|}
\hline Antibiotics & $\begin{array}{l}\text { Morganella } \\
\text { morgannii }\end{array}$ & $\begin{array}{l}\text { Enterobacter } \\
\text { spp }\end{array}$ & $\begin{array}{l}\text { Proteus } \\
\text { spp }\end{array}$ & $\begin{array}{l}\text { Raoultella } \\
\text { planticola }\end{array}$ & $\begin{array}{l}\text { Klebsiella } \\
\text { pneumoniae }\end{array}$ & $\begin{array}{l}\text { Pseudomonas } \\
\text { putida }\end{array}$ & $\begin{array}{l}\text { Enterococcus } \\
\text { faecalis }\end{array}$ & $\begin{array}{l}\text { Staphylococcus } \\
\text { aureus }\end{array}$ \\
\hline Ertapenem & $11 / 11$ & $4 / 4$ & $2 / 2$ & $1 / 1$ & $1 / 1$ & - & - & $1 / 1$ \\
\hline Imepenem & $11 / 11$ & $4 / 4$ & $2 / 2$ & $1 / 1$ & $1 / 1$ & - & - & $1 / 1$ \\
\hline Meropenem & $11 / 11$ & $4 / 4$ & $2 / 2$ & $1 / 1$ & $1 / 1$ & $0 / 1$ & - & $1 / 1$ \\
\hline Cefuroxime & $11 / 11$ & $4 / 4$ & $2 / 2$ & $1 / 1$ & $1 / 1$ & - & - & $1 / 1$ \\
\hline Ceftazidime & $11 / 11$ & $4 / 4$ & $2 / 2$ & $1 / 1$ & $1 / 1$ & $1 / 1$ & - & $1 / 1$ \\
\hline Ceftriaxone & $11 / 11$ & $4 / 4$ & $2 / 2$ & $1 / 1$ & $1 / 1$ & - & - & $1 / 1$ \\
\hline Cefotaxime & $11 / 11$ & $4 / 4$ & $2 / 2$ & $1 / 1$ & $1 / 1$ & - & - & - \\
\hline Cefepime & $11 / 11$ & $4 / 4$ & $2 / 2$ & $1 / 1$ & $1 / 1$ & - & - & - \\
\hline $\begin{array}{l}\text { Piperacillin/ } \\
\text { Tazobactam }\end{array}$ & $11 / 11$ & $4 / 4$ & $2 / 2$ & $1 / 1$ & $1 / 1$ & - & - & $1 / 1$ \\
\hline Gentamicin & $11 / 11$ & $4 / 4$ & $2 / 2$ & $1 / 1$ & $1 / 1$ & - & $27 / 27$ & \\
\hline Tobramycin & $11 / 11$ & $4 / 4$ & $2 / 2$ & $1 / 1$ & $1 / 1$ & - & - & \\
\hline Amikacin & $11 / 11$ & $4 / 4$ & $2 / 2$ & $1 / 1$ & $1 / 1$ & $1 / 1$ & - & \\
\hline Ciprofloxacin & $11 / 11$ & $4 / 4$ & $2 / 2$ & $1 / 1$ & $1 / 1$ & $1 / 1$ & - & \\
\hline Levofloxacin & $11 / 11$ & $4 / 4$ & $2 / 2$ & $1 / 1$ & $1 / 1$ & $1 / 1$ & - & \\
\hline $\begin{array}{l}\text { Trimethoprime/ } \\
\text { Sulfamethazole }\end{array}$ & $11 / 11$ & $4 / 4$ & $2 / 2$ & $1 / 1$ & $1 / 1$ & - & - & \\
\hline Fosmycin & $0 / 11$ & $0 / 4$ & $2 / 2$ & $1 / 1$ & $1 / 1$ & - & - & \\
\hline Ampicilin & - & - & - & - & - & - & $27 / 27$ & \\
\hline Piperacillin & - & - & - & - & - & - & $27 / 27$ & \\
\hline Chloramphenicol & - & - & - & - & - & - & $27 / 27$ & \\
\hline Vancomycin & - & - & - & - & - & - & $27 / 27$ & \\
\hline Linezonid & - & - & - & - & - & - & $27 / 27$ & $1 / 1$ \\
\hline $\begin{array}{l}\text { Amoxicillin/Acid } \\
\text { clavulanic }\end{array}$ & - & - & - & - & - & - & $27 / 27$ & $1 / 1$ \\
\hline $\begin{array}{l}\text { Ampicillin/ } \\
\text { Sulbactam }\end{array}$ & - & - & - & - & - & - & $27 / 27$ & - \\
\hline $\begin{array}{l}\text { Piperacillin/ } \\
\text { Tazobactam }\end{array}$ & - & - & - & - & - & - & $27 / 27$ & - \\
\hline
\end{tabular}

which might be because patients had minor inflammatory lesions or dry wounds leading to inoculation without bacteria.

In our study setting, early antibiotic use with a combination of clindamycin and ciprofloxacin could be indicated to prevent wound necrosis and infection. In Brazilian studies, chloramphenicol was the first-line antibiotic for Bothrops snakebite owing to the presence of $M$ morganii, Providencia rettgeri, Enterobacter spp, Escherichia coli, Enterococcus spp, and Bacteroides spp. ${ }^{17}$ Benzylpenicillin and gentamicin were used as prophylaxis for Malayan snakebite in which Enterobacter spp, Pseudomonas spp, Staphylococcus, and Clostridium were isolated from snakes' oral cavity. ${ }^{18}$ Piperacillin monotherapy or a combination of penicillin A with third-generation cephalosporin or fluoroquinolone were considered first-line antibiotics for local wound infection associated with Naja atra bite. ${ }^{15}$ In our study, all isolated bacteria were sensitive to ciprofloxacin, and all wound infections resolved with ciprofloxacin.

There were several limitations to the study. Although this was a single-center study, cases were referred from all near provinces, making these findings generalizable to these areas as well. Second, unless the snake was identified directly, the cases were presumed to be Naja spp through assessment and description of the snake provided to toxicology clinicians at Bach Mai Hospital. Third, no information was collected on bacterial superinfection after therapeutic or traditional medicine intervention by a local healer or patients. In practice, snake oral flora bacteria were susceptible to most antibiotics. ${ }^{2,15}$ 


\section{Conclusions}

Wound necrosis and infection were important clinical issues in presumed Naja spp snakebites. Morganella morganii and Enterococcus faecalis were dominant in local wound swabs of such cases. Ciprofloxacin should be an effective first-line antibiotic for patients with presumed Naja bite.

Author Contributions: Study concept and design (NDN, TTM, QXL, AQP, NTN, HHT, TQL); formal analysis (NDN, QXL, TTM, AQP); investigation (NDN, TTM, QXL, AQP, NTN, HHT, TQL). All authors drafted the manuscript and approved final manuscript.

Financial/Material Support: None.

Disclosures: None.

\section{References}

1. World Health Organization. Snakebite envenoming. Geneva, Switzerland: World Health Organization; 2019.

2. Shek KC, Tsui KL, Lam KK, Crow P, Ng KH, Ades G, et al. Oral bacterial flora of the Chinese cobra (Naja atra) and bamboo pit viper (Trimeresurus albolabris) in Hong Kong SAR, China. Hong Kong Med J. 2009;15(3):183-90.

3. Wüster W. Taxonomic changes and toxinology: systematic revisions of the Asiatic cobras (Naja naja species complex). Toxicon. 1996;34(4):399-406.

4. Blessmann J, Nguyen TPN, Bui TPA, Krumkamp R, Vo VT, Nguyen HL. Incidence of snakebites in 3 different geographic regions in Thua Thien Hue province, central Vietnam: green pit vipers and cobras cause the majority of bites. Toxicon. 2018;156:61-5.

5. Clark RF, Selden BS, Furbee B. The incidence of wound infection following crotalid envenomation. J Emerg Med. 1993;11(5):583-6.

6. Gardner SE, Frantz RA, Doebbeling BN. The validity of the clinical signs and symptoms used to identify localized chronic wound infection. Wound Repair Regen. 2001;9(3):178-86.

7. Persson HE, Sjoberg GK, Haines JA, Pronczuk de Garbino J. Poisoning severity score. Grading of acute poisoning. J Toxicol Clin Toxicol. 1998;36(3):205-13.
8. Wong OF, Lam TS, Fung HT, Choy CH. Five-year experience with Chinese cobra (Naja atra)-related injuries in two acute hospitals in Hong Kong. Hong Kong Med J. 2010;16(1):36-43.

9. Guo MP, Wang QC, Liu GF. [Pharmacokinetics of cytotoxin 14 from Naja naja atra venom]. Zhongguo Yao Li Xue Bao. 1992;13(6):544-6.

10. Anz AW, Schweppe M, Halvorson J, Bushnell B, Sternberg M, Koman LA. Management of venomous snakebite injury to the extremities. J Am Acad Orthop Surg. 2010;18(12):749-59.

11. Wang W, Chen QF, Yin RX, Zhu JJ, Li QB, Chang HH, et al. Clinical features and treatment experience: a review of 292 Chinese cobra snakebites. Environ Toxicol Pharmacol. 2014;37(2):648-55.

12. Wongtongkam N, Wilde $\mathrm{H}$, Sitthi-Amorn C, Ratanabanangkoon K. A study of Thai cobra (Naja kaouthia) bites in Thailand. Mil Med. 2005;170(4):336-41.

13. Gutierrez JM, Leon G, Lomonte B. Pharmacokinetic-pharmacodynamic relationships of immunoglobulin therapy for envenomation. Clin Pharmacokinet. 2003;42(8):721-41.

14. Goldstein EJ, Citron DM, Gonzalez H, Russell FE, Finegold SM. Bacteriology of rattlesnake venom and implications for therapy. J Infect Dis. 1979;140(5):818-21.

15. Mao YC, Liu PY, Hung DZ, Lai WC, Huang ST, Hung YM, et al. Bacteriology of Naja atra snakebite wound and its implications for antibiotic therapy. Am J Trop Med Hyg. 2016;94(5):1129-35.

16. Garg A, Sujatha S, Garg J, Acharya NS, Parija SC. Wound infections secondary to snakebite. J Infect Dev Ctries. 2009;3(3):221-3.

17. Jorge MT, Ribeiro LA, da Silva ML, Kusano EJ, de Mendonça JS. Microbiological studies of abscesses complicating Bothrops snakebite in humans: a prospective study. Toxicon. 1994;32(6):743-8.

18. Theakston RD, Phillips RE, Looareesuwan S, Echeverria P, Makin T, Warrell DA. Bacteriological studies of the venom and mouth cavities of wild Malayan pit vipers (Calloselasma rhodostoma) in southern Thailand. Trans $R$ Soc Trop Med Hyg. 1990;84(6):875-9. 